This item was submitted to Loughborough's Research Repository by the author.

Items in Figshare are protected by copyright, with all rights reserved, unless otherwise indicated.

\title{
Instrumentation and early-age monitoring of concrete slabs
}

PLEASE CITE THE PUBLISHED VERSION

PUBLISHER

(c) Institution of Civil Engineers / Thomas Telford

VERSION

NA (Not Applicable or Unknown)

LICENCE

CC BY-NC-ND 4.0

REPOSITORY RECORD

Austin, Simon A., Peter J. Robins, and Jonathan W. Bishop. 2019. "Instrumentation and Early-age Monitoring of Concrete Slabs". figshare. https://hdl.handle.net/2134/4032. 
This item was submitted to Loughborough's Institutional Repository (https://dspace.lboro.ac.uk/) by the author and is made available under the following Creative Commons Licence conditions.

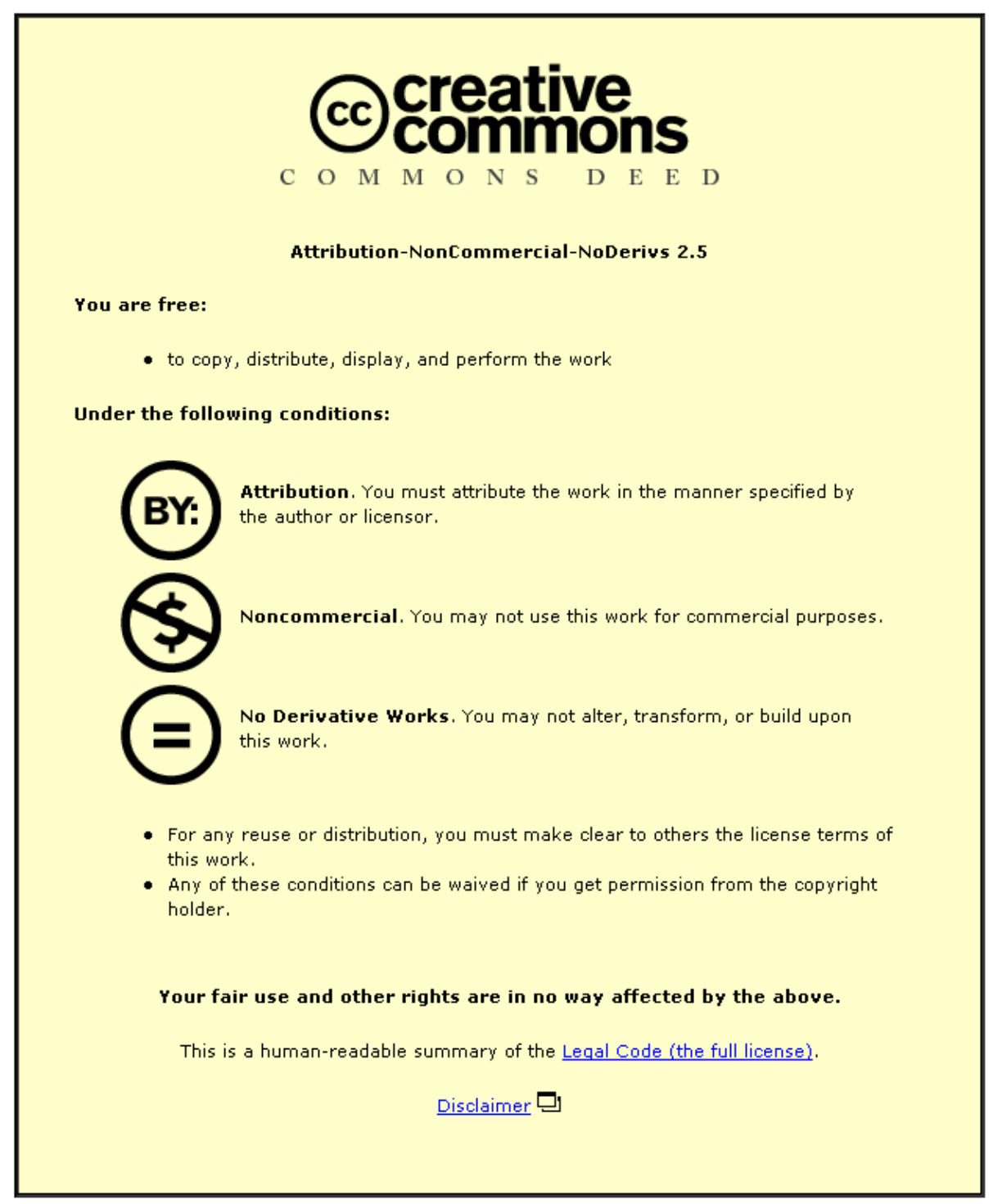

For the full text of this licence, please go to: http://creativecommons.org/licenses/by-nc-nd/2.5/ 


Proceedings of the Institution of
Civil Engineers
Structures \& Buildings 159
August 2006 Issue SB4
Pages 187-195
Paper 13414
Received 27/06/2003
Accepted 23/03/2006
Keywords:
concrete structures/field testing \&
monitoring/slabs \& plates

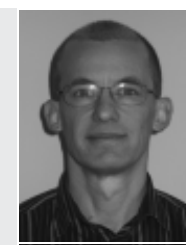

Simon A. Austin Chair in Structura Cngineering, Department of University, UK E Engineering, Loughboroug University, UK

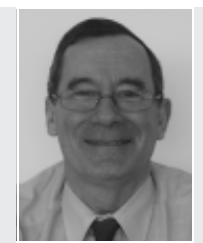

Peter J. Robins

Senior lecturer, Department of Civil and Building Engineering, Loughborough University,

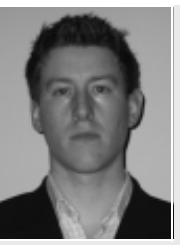

onathan W. Bishop

Senior applications consultant, Customer Systems plc, Chertsey, UK (formerly Research assistant, Department of Civil and Building Engineering, Loughborough University, UK

\title{
Instrumentation and early-age monitoring of concrete slabs
}

\author{
S. A. Austin PhD, CEng, MICE, P. J. Robins PhD, CEng, MICE and J. W. Bishop PhD
}

This paper reports the instrumentation and monitoring techniques developed to improve understanding of the early-life behaviour of concrete industrial ground-floor slabs. Concrete strains, temperatures and joint movements were measured using vibrating-wire embedment strain gauges and thermistors, while ambient conditions were monitored to assess their effects. A reliable, accurate and easy-to-implement methodology, developed by instrumenting four types of floor slab (mesh-reinforced long strip, mesh-reinforced jointed large area pour, steel fibre-reinforced jointed large area pour and steel fibre-reinforced jointless large area pour) is described in detail, along with the further developments and modifications to the instrumentation. The methodology developed would be equally applicable to the early-life monitoring of other concrete structural elements. Some sample results of data gathered using the instrumentation methodology developed are included.

\section{INTRODUCTION}

Many areas of construction have seen major changes over the last two decades with the increase in mechanisation and resulting changes in working practices. In some areas these changes have simply allowed increased productivity, whereas in others completely new construction techniques have been adopted to exploit the new technology. These new construction techniques can affect the behaviour of the structure, in some cases requiring changes to design practices, guides and codes.

This three-year research project was undertaken with support from the Engineering and Physical Sciences Research Council (EPSRC) and 12 industrial organisations to monitor and model the behaviour of concrete industrial ground floors, where a revolution in construction techniques has left engineers with serious gaps in design guidance. More specifically, the project aimed to improve the understanding of how the early-age development of the concrete's material properties can interact with the climate and curing along with the form of construction (joints, reinforcement and slab restraint) to produce a suitably low-stressed concrete that can efficiently carry the subsequent stresses resulting from the imposed loads. ${ }^{1}$

This aim of the current paper is to describe the development and implementation of the in situ monitoring technique in the context of industrial ground floor slabs, although the same basic principles can be applied to any concrete structural member. Several stages of development had to be undergone before arriving at a methodology that has proved practicable, reliable and robust. Most of the modifications resulted from the need to cope with a variety of site conditions and construction techniques, and were associated with the instrumentation at specific locations in the slab, and with the methods used to prepare, transport and install the instrumentation. Some of these modifications are described in order to prevent other investigators suffering from the same problems, although for the sake of brevity a step-by-step description of the development is not given. The current authors acknowledge the comments made in The Structural Engineer by Smith ${ }^{2}$ regarding the need for practical advice for practising engineers, and intend the current paper to give new insights into the techniques available for early-age monitoring of concrete structural elements. The findings from the instrumentation of seven sites, discussing the influence of thermal and hygral effects on slab and joint movements, are presented elsewhere ${ }^{3,4}$ as are the results of finite element modelling of the slab behaviour. ${ }^{5}$ Further information on the research can also be found on the project website. ${ }^{6}$

\section{THE IMPORTANCE OF IN SITU DATA FOR DESIGN}

Engineers have to make assumptions and idealise behaviour when designing any structure. This is because design techniques are approximations that simplify the problem to the point where it can be solved relatively simply and quickly. A quick, and thus simplified, analysis is also required to meet the economic demands of having a structure designed, constructed and in use as quickly as possible. Assumptions and simplifications can however introduce errors, particularly if they are applied in situations for which they were not intended.

Instrumentation can provide useful performance data on most structures which may then be compared with the predicted values to verify design methods. Also, there are groups of structures that are similar in construction where in situ performance data would help in the development of more efficient designs for the future. For industrial floors the main design guidance available to engineers in the UK is the Concrete Society Technical Report 34, ${ }^{7,8}$ which gives advice on the detail and structural design of concrete ground-floor slabs. Most of the detail design guidance contained in the 1994 
version of TR $34^{7}$ was empirical and based on out-of-date construction methods; also the limited theory was largely unsubstantiated. New construction forms (specifically fibre reinforced and large area pours) and greater performance requirements from clients resulted in the need for a better theoretical understanding and revised design guidance to be made available to engineers if uneconomic solutions and costly failures are to be avoided. Some form of in situ monitoring of the behaviour of the slabs was seen as being essential in achieving a better understanding of slab behaviour. TR34 has now been fully revised by the Concrete Society and the Association of Concrete Industrial Flooring Contractors (ACIFC) through a Partners in Innovation Project. ${ }^{8}$ It embodies many of the findings from this collaborative research project, based on a combination of site instrumentation and theory.

\section{CHOICE OF INSTRUMENTATION}

\section{I. Identification of key parameters}

A number of key features were identified as being relevant to the study of the early-age behaviour of concrete structures.

(a) Information on the movement of the concrete was of prime interest, particularly that associated with the shrinkage of the slab. Key locations such as joints, points of restraint and openings were identified and instrumented. This involved instrumenting construction joints and induced joints as well as concrete within bays to determine the effects of restraint.

(b) The measured movements in the concrete are dependent on the concrete's internal relative humidity and temperature: sensors were therefore used to determine the internal profiles of these parameters.

(c) The atmospheric environment (air speed, ambient temperature and relative humidity $(\mathrm{RH})$ ), which controls the rate of moisture loss from the slab and is the driving function of the internal temperature changes, was also monitored.

The sensors had to be capable of being monitored by a computercontrolled datalogger. This allowed them to be sampled at different frequencies to suit their rate of change and the age of the slab. Site access was then only required periodically to download the stored data onto a laptop computer.

\subsection{Atmospheric conditions}

The choice of instrumentation for the ambient conditions was relatively straightforward as these parameters are routinely monitored in weather stations. A Vaisala-type temperature and $\mathrm{RH}$ probe housed in a radiation shield was used. This had an accuracy of $\pm 1 \%$ RH compared with a factory reference and a long-term stability of better than $1 \% \mathrm{RH}$ per year, while the temperature readings were made to an accuracy of $\pm 0 \cdot 2^{\circ} \mathrm{C}$ at $20^{\circ} \mathrm{C}$. Air movement was recorded by two digital switched anemometers that were fixed to a column at right angles to each other to prevent the effects of wind shadow, caused by the supporting column, from affecting the readings.

\subsection{Concrete and sub-base conditions}

Type $\mathrm{T}$ thermocouples were chosen to measure the thermal profile through the slab and into the sub-base because they were well suited to the temperature ranges that would be encountered during the hydration and service life of the slabs and they are the only thermocouple type which is suited to a damp environment. Additionally they were cheap to install over relatively large distances and the small size and low specific heat capacity means that there is minimal latency in the measured temperature response.

Chilled mirror probes were chosen to monitor the concrete internal $\mathrm{RH}$, dew-point and temperature because of their high degree of accuracy and long-term stability. By optically measuring the formation of dew on a mirror, which is alternately heated and cooled, these sensors are both very precise and resistant to contamination, giving good long-term stability. As a result of the technology involved in the sensor head these instruments are fragile and expensive, which does not make a good combination for site work.

Vibrating wire (vw) strain gauges were chosen to monitor the behaviour of the concrete because they have

(a) a very high resolution, allowing readings to be taken to a precision of less than 1 microstrain

(b) long-term stability of less than 1 microstrain per year, preventing systematic drift affecting the results

(c) a very low stiffness $\left(\sim 40 \mathrm{~N} / \mathrm{mm}^{2}\right)$, allowing readings to be taken within $4 \mathrm{~h}$.

A laboratory and numerical study by Boulay and Paties ${ }^{9}$ of the interaction between early-age concrete and a vw strain gauge found that, once the concrete modulus had exceeded $1500 \mathrm{MPa}$, the errors between the measured and imposed deformations owing to thermal or structural loads were less than 5\%. It was found that the thermal deformations were overestimated by the gauges at early ages, while the structural deformations were underestimated. This is believed to be because the concrete was not sufficiently strong to transfer structural loads to the gauges or to restrain the gauge under applied thermal loads. The results were found to be dependent on the geometry of the specimen and of the gauge. The thermal coefficient of expansion of the gauge wire is $11 \mu \mathrm{strain} /{ }^{\circ} \mathrm{C}$, which is very similar to that of concrete $\left(10 \mu \text { strain } /{ }^{\circ} \mathrm{C}\right)^{10}$ meaning thermal effects will be negligible, but also easily corrected. Thermistors located in the coil housing of the strain gauges measured slab temperature allowing thermal corrections to be applied to the readings, while also providing more thermal data to be added to those collected by the thermocouples.

Readings from the vw strain gauges rely on a measurement of the resonant frequency, removing all dependence on the conductance of the connecting wire. Thus flexibility was maintained on site, allowing changes in the gauge layout and the cable lengths to suit the construction schedules, without requiring any re-calibration of the sensors.

The monitoring of dynamic effects fell outside the remit of this research, which was only intended to monitor the slabs before they went into service, although it was intended to produce instrumentation layouts that would be flexible enough to provide useful long-term performance data. More recent work has led to the development of a device that excites vw gauges using a feedback loop allowing them to monitor dynamic loads. Many industrial ground-floor failures are related to 
excessive joint movement in service. There are currently few data on the dynamic movement of joints; it is however possible that this device may allow further use of the instrumentation already in place to monitor joint and slab behaviour under these dynamic loads.

\subsection{Datalogger}

The datalogger formed the heart of the instrumentation and had to provide flexibility of use while being easy and intuitive to program and wire up. The chosen datalogger had six double or 12 single-ended channels, which could be expanded by adding multiplexers allowing up to 32 instruments to go to a single datalogger channel. ${ }^{11}$

The datalogger control programs were written using MS Windows ${ }^{\circledR}$-based software allowing complicated programs to be written quickly and easily. Control flags, set manually using a laptop computer connected to the datalogger, were used to control the activation of different parts of the program, as well as time-dependent controls. In this way it was possible to activate the monitoring of gauges in several phases corresponding to the construction sequence. It was also possible to reduce the sample frequency incrementally as the slab aged. As the datalogger only had a finite storage space, decreasing the frequency of readings to match the slowing rate of shrinkage with time allowed a greater period of time between site visits to download the data.

\section{DEVELOPMENT OF INSTRUMENTATION METHODS}

\section{I. Introduction}

The methods used to instrument industrial floors were arrived at over a period of 14 months and four instrumentations. A total of seven slabs (at six sites) were instrumented and monitored, encompassing four different slab types: (a) meshreinforced long strip; $(b)$ mesh-reinforced jointed large area pour $(\times 3)$; (c) steel fibre-reinforced jointed large area pour; and, $(d)$ steel fibre-reinforced jointless large area pour $(\times 2)$. Several modifications were required to overcome problems related to the specific construction methods employed in the construction of industrial floors. A reliable and quick methodology was finally developed for monitoring the concrete strains and joint movements; however, some problems remained unsolved owing to incompatibilities between the sensors and the conditions on site. For example, the ambient $\mathrm{RH}$ and temperature probe proved susceptible to contamination owing to the very dusty environment on site, which affected the accuracy of the readings. The timescale over which this contamination occurred varied from several days to several months. No alternative method for monitoring the ambient $\mathrm{RH}$ was feasible, but it was possible to estimate the ambient RH using ambient temperature and atmospheric pressure data supplied by the British Atmospheric Data Centre.

\subsection{Gauge types}

Laboratory experiments and a site trial were undertaken to evaluate the performance of the vw strain gauges and to assess how they would stand up to the construction methods. This also gave an opportunity to investigate the gauge-fixing technique and different methods for connecting the gauges to the datalogger, while allowing the collection of some early performance data on one of the slab types.

The strain gauges were suspended from piano wire, which was passed through holes drilled in the flange plates (Fig. 1). This method of attachment imposed minimal longitudinal restraint, and minimised the amount of additional reinforcement in the area around the gauge, thus causing the least modification to the concrete being monitored. As the reinforcement was located in the top of the slab (with $50 \mathrm{~mm}$ cover) it was possible to attach the piano wire carrying the gauges to the chairs supporting the reinforcement at a range of depths and orientations (Fig. 2).

This method had to be modified for large area pours, as fixing
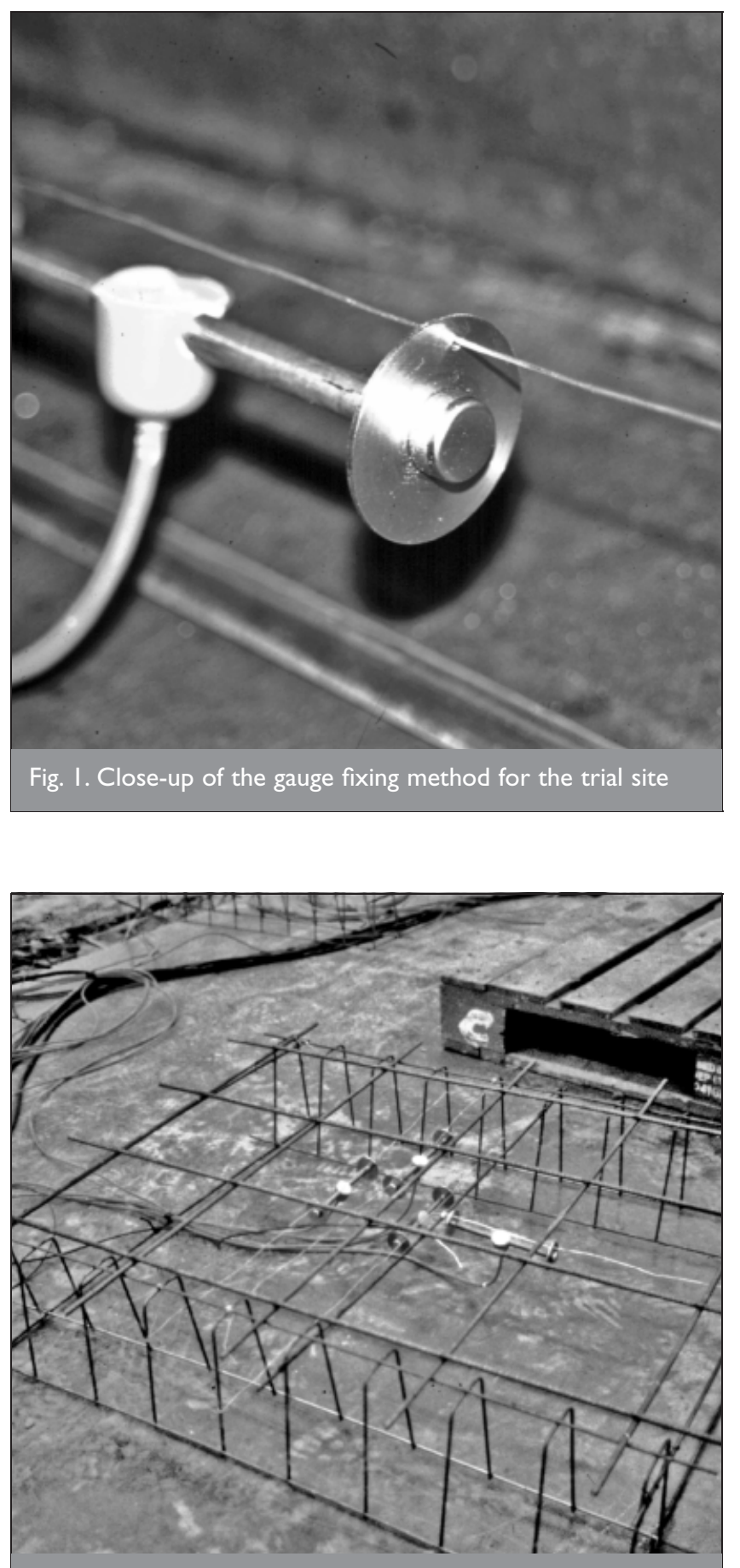

Fig. 2. Strain gauges suspended from the reinforcement chairs 
the gauges to piano wire was found to give too much freedom of movement. The solution was to cable-tie the strain gauges to reinforcement chairs with a length of silicone tubing placed between the gauge barrel and the chair to prevent movement and damage to the gauge. The chairs were then taped to the slip membrane (Fig. 3), or, in the case of fabric reinforced floors, were cable-tied to the reinforcement (Fig. 4).

\subsection{Interface box and cabling system}

It became apparent during the planning stage for the trial instrumentation that a large number of cables would need to be connected to the datalogger. For simplicity, and in order to save time in preparing for future site instrumentations, a standard datalogger set-up was devised that allowed up to 80 vw strain gauges to be monitored (including 12 with internal thermistors), as well as the ambient probes and an array of thermocouples. This standardisation meant that the dataloggers were interchangeable between sites, with only the correct control program needing loading up.

An interface box was designed to allow this standardisation and enable the dataloggers to be removable. This provided a neat, waterproof and inconspicuous termination to the multicore cables and also facilitated their re-ordering to accommodate the common datalogger set-up. In order to simplify the control program, all of the strain gauges with thermistors were sampled first, followed by all of the acrylic barrelled gauges and finally the steel barrelled gauges. As the
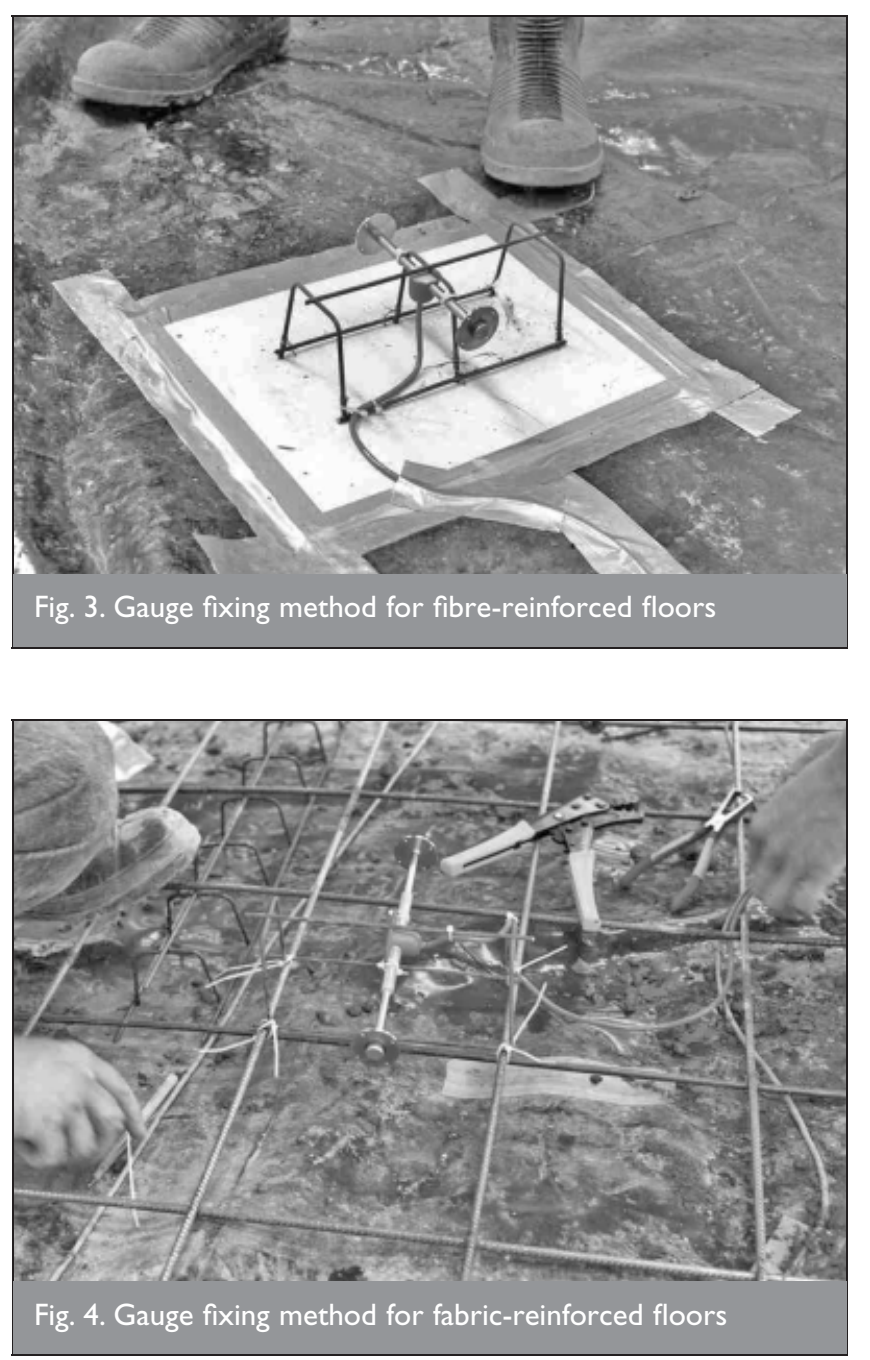

gauge layout for each site was different, the numbers and locations of these gauges changed each time, but by reordering the cables in the interface box the impact on the datalogger was minimised. This allowed the dataloggers to be removed, moved to a different site and then put back at a later date, if required. By preparing this box in the laboratory, testing was carried out on the finished wiring loom under controlled conditions, making faults easier to spot and rectify.

Early interface boxes used 15-way RS 232 connectors to attach the cables from the gauge clusters. These terminations were, however, time-consuming to produce and were difficult to secure on site, leading to the adoption of a hardwiring system, where all of the wires were fixed directly into terminal strips inside the interface box. Although this made transportation slightly more difficult, this modification reduced the time required to produce the interface box and, because the terminal strips were quick and convenient to connect to the vw strain gauge manual read-out box, the process of taking manual readings was simplified.

After the site trial, which had only used four 25-way RS232 connectors to link the interface box to the datalogger, the monitoring capacity was increased requiring six 25-way RS232 connectors. A spreadsheet was developed to keep track of the gauge numbers and locations as well as the colours of the large numbers of wires connecting them to the logger. Once the spreadsheet had been completed it was also used when programming the datalogger, as it provided a complete record of how every gauge was connected.

Two options for connecting the strain gauges to the interface box were identified (Fig. 5), namely

(a) individual cable runs for all gauges

(b) clusters of gauges connected with multi-core cable.

Individual cable runs cost $£ 1 \cdot 15 / \mathrm{m}$ compared with $£ 0 \cdot 70 / \mathrm{m}$ for 12-core cable capable of carrying the signals from up to six strain gauges. The cost of cabling a typical instrumentation layout using 20 gauges over a $40 \mathrm{~m}$ length using individual cable runs would have been $\sim £ 500$ as opposed to less than $£ 100$ using multi-core cable, even allowing for the cost of the cluster boxes. Thus, given the large areas to be monitored, the

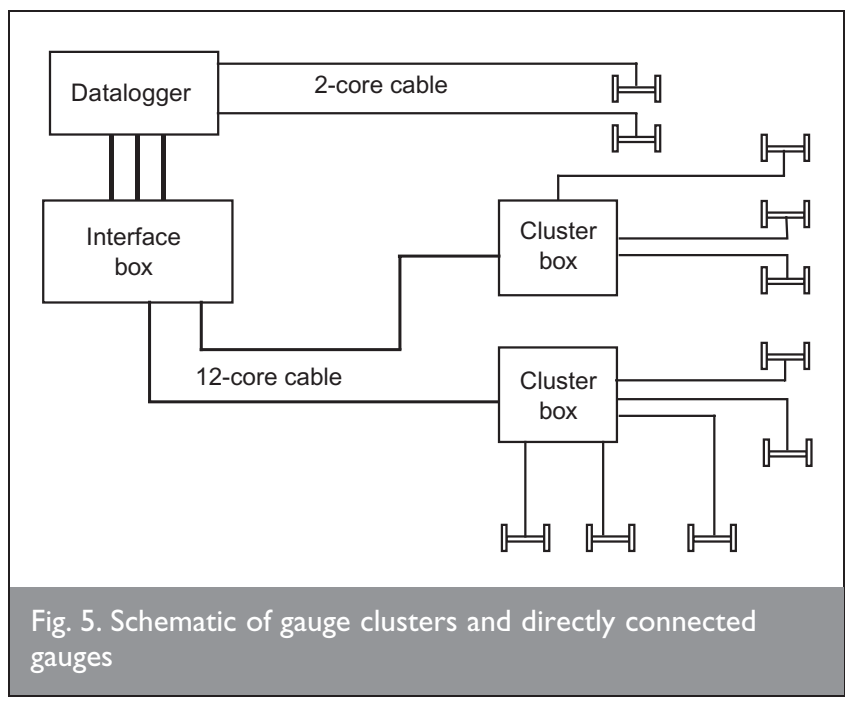


economic argument in favour of gauge clusters and multi-core cable runs was clear.

This method for connecting the strain gauges to the interface box was verified on the trial site. An unacceptable number of gauges were, however, lost in the first large area pour because the force of the moving concrete as it was poured broke some of the wiring connections. This problem was solved in future trials by using cable glands in the cluster boxes and by cabletying a loop into the leads at all connections to keep the crimps free of stress (Fig. 6). The joints were then taped up to prevent the ingress of moisture from the concrete.

Various methods were tried to protect the multi-core cables connecting the cluster boxes to the interface box, though burying the cables in the sub-base proved to be the most efficient. Once the cables had been protected none of the cables were damaged by the normal trafficking of the floor.

\subsection{Gauge layout/planning}

Various gauge layouts were used to attempt to measure differential movement through the thickness of the slab, at different distances from the joints, in both longitudinal and transverse directions and at the joints themselves. The gauge layout also reflected the type of floor being constructed, that is, a jointless pour had few joint gauges and more embedment gauges monitoring movement at different distances from the joints.

\subsection{Long strain gauges}

The range of movement a vw strain gauge can measure is dependent on its length, so locations where larger movements could reasonably be expected were instrumented using longer strain gauges. Standard vw strain gauges were $140 \mathrm{~mm}$ long, and had a quoted range of 3000 microstrain, which equated to a measurable movement of $0.42 \mathrm{~mm}$. In order to measure across joints, $254 \mathrm{~mm}$ long strain gauges were developed (Fig. 7). These gauges had an increased frequency response because of their increased length and, additionally, any strain reading represented a larger movement than for a small gauge because of the increased gauge length. Thus these $254 \mathrm{~mm}$ strain gauges had a quoted range in excess of $1 \mathrm{~mm}$, although readings from these gauges exceeded 10000 microstrain $(2.5 \mathrm{~mm})$ before failure. The additional length of these joint gauges also gave a greater margin for error in locating the gauges across the intended position of the saw-cut joints.

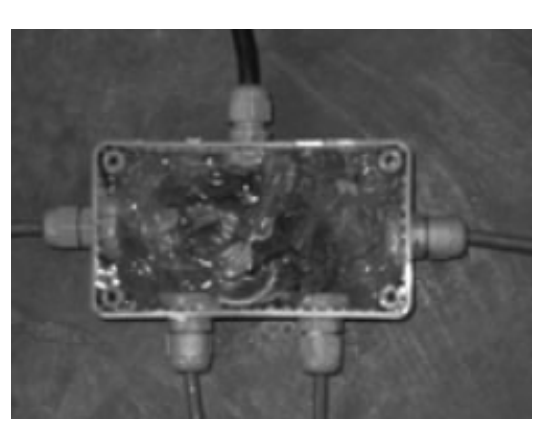

Fig. 6. Open cluster box

\subsection{Day-joint gauges}

Although monitoring across induced joints, such as saw-cut joints in concrete slabs, proved possible with the $254 \mathrm{~mm}$ gauges, trying to monitor across day joints was difficult as part of the gauges was left exposed once the slab had been cast (Fig. 7). After several gauges were damaged because it proved difficult to protect the gauges adequately, a new gauge with a removable extension arm was developed in association with Gage Technique International (Fig. 8).

The vw part of the gauge was embedded in the first pour with the end block attachment for the extension arm protected by polystyrene (Fig. 9). Once the formwork had been removed, the polystyrene was broken out leaving the end block ready for connection of the extension arm just prior to the commencement of the second pour (Fig. 10).

This newly developed gauge can be used in any situation where monitoring is required across day joints, or indeed in any situation where phased construction is being used and a part of the gauge might otherwise be left exposed for any period of time.

\subsection{Paired gauges}

Even using the $254 \mathrm{~mm}$ strain gauges, the range of measured movement is small in terms of that which could be expected at joints, even at early ages. In order to increase the monitored range of joint opening where permission could not be obtained
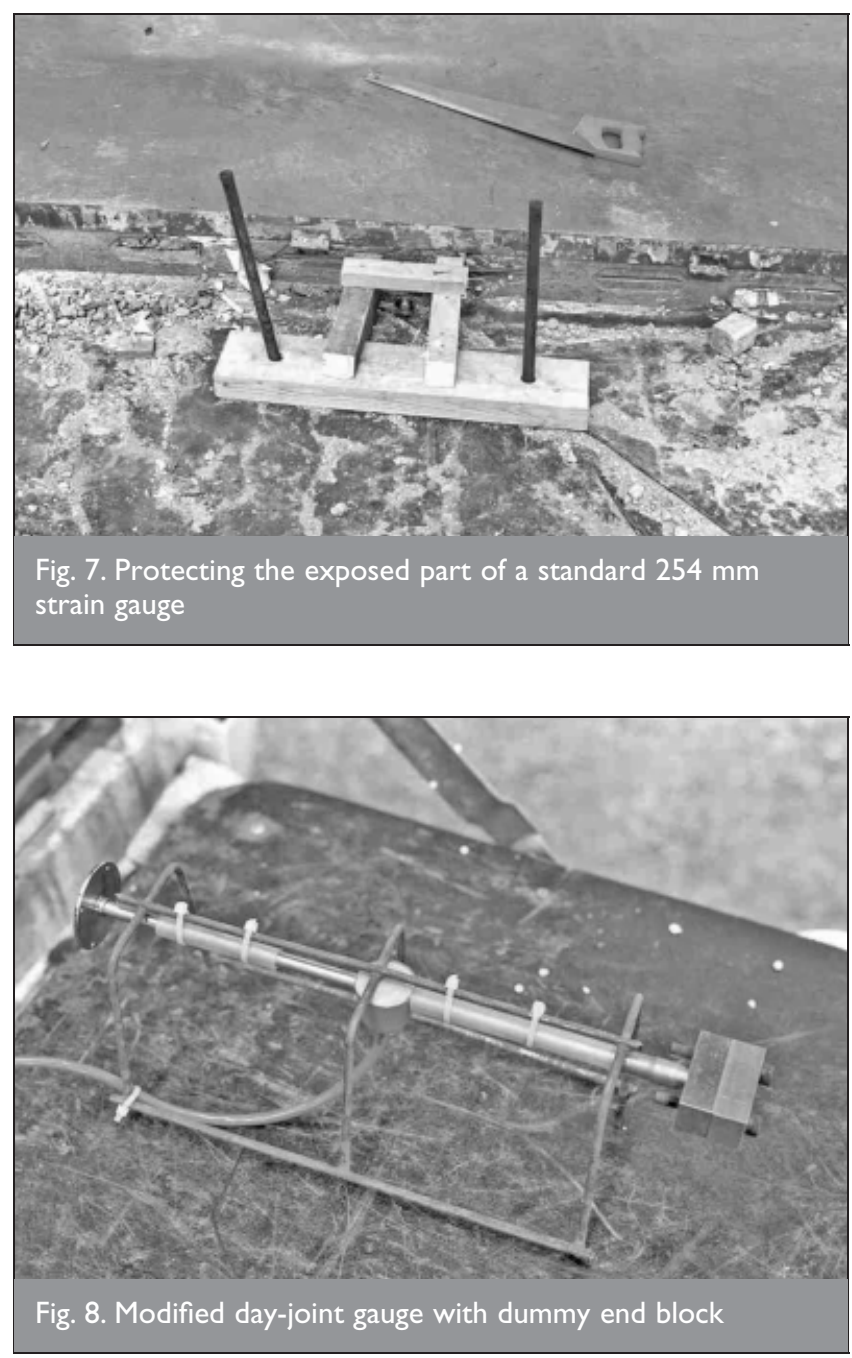

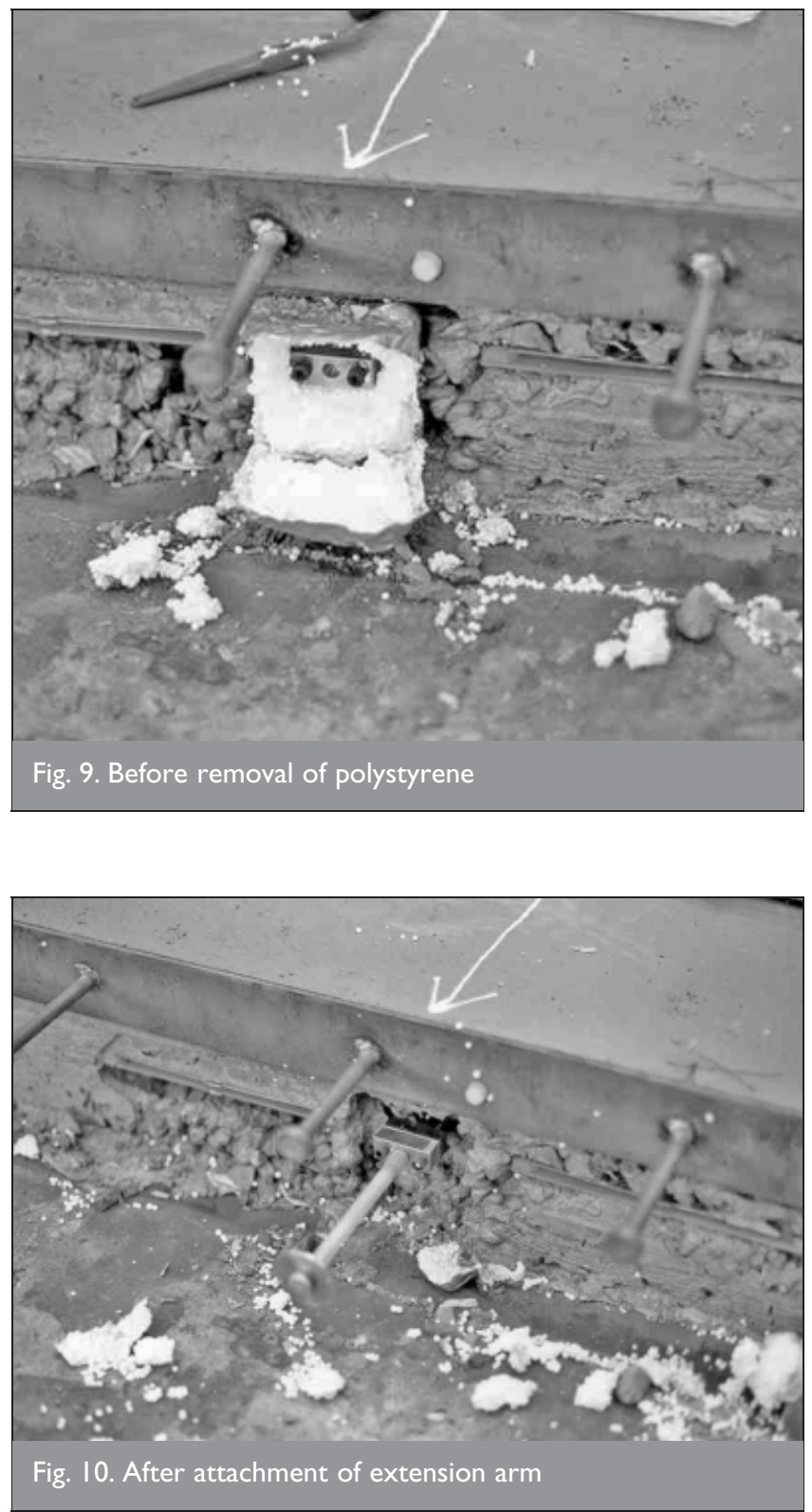

from the client to install Demec pips in the surface of the floor, pairs of strain gauges were used. The wire in the first gauge was set normally, while that in the second gauge was initially slack. As the joint opened the wire in the slack gauge tensioned up and began to take readings before the wire in the first gauge failed.

Although these proved to be successful, the additional cost did not realise much additional range of movement, and if the first gauge is damaged the readings from the second gauge are of no use. In order to reduce this risk it is recommended that a Demec gauge reading pips located in small holes in the surface of the concrete on either side of the joint should be used for monitoring large joint movements. By combining these two methods, the joint gauges can give information on the timing and magnitude of the early movement, while the Demec gauge can provide long-term joint opening information.

\subsection{Chilled mirror probes}

Chilled mirror probes cannot be placed into wet concrete, requiring the use of a removable $25 \mathrm{~mm}$ diameter metal bar inside a length of plastic conduit as a blank. The conduit prevented moisture loss from all depths in the slab once the probe was inserted, allowing the measurement of moisture at specific depths. The plastic tube extended above the surface of the slab and provided some support for the probes. It proved difficult, however, to provide any real protection without damaging the surface of the floor. For this reason the probes could not be used for long, having to be removed before the building became operational.

\section{FINAL INSTRUMENTATION METHODOLOGY}

The final site instrumentation methodology is now described in detail. This has been broken up chronologically, with one section detailing the work to be carried out before transportation to site, another covering the actions once the instrumentation is on site and the final section dealing with post construction activities.

\section{I. Pre-site preparation}

Once the areas to be instrumented had been chosen, a location for the datalogger had to be found. Ideally the datalogger should be fairly central in the area of interest, yet also away from frequently trafficked areas, unless some form of protection can be assured. Once the position of the datalogger had been determined, the strain gauge locations were then chosen: generally all joints were instrumented and at least one gauge was placed between each pair of joints to measure the concrete shrinkage. Where possible, more than one gauge was placed at each location to provide a degree of redundancy. This allowed performance data to be gathered from two different depths in the slab when both gauges worked, and if one gauge failed there were still data from the remaining gauge. Once the gauge locations and types were finalised they were grouped into clusters of up to six gauges for connection to the interface boxes. The gauge positioning information was entered into a spreadsheet to allow the wires from each cluster box to be identified. This spreadsheet was then used to produce the wiring plan for the interface box, allowing for the rearrangement of the gauges to suit the standardised datalogger.

The decision to use this standard datalogger arrangement meant that the multiplexers only had to be wired-up to the datalogger and connected to 25-way RS232 connectors once. This was time-consuming and care had to be taken to avoid errors, which could lead to sensors being misidentified or misread by the logger.

The datalogger control programs were written to allow automatic sampling of the gauges at predetermined rates depending on the number of gauges, the age of the slab and the expected time between site visits. Normal time scales were every half hour for the first $24 \mathrm{~h}$, hourly for the first week and then 3 or 4 hourly thereafter. A manual override activated by a control flag was also provided to increase the sampling frequency of the gauges to once every $2 \mathrm{~min}$. This was used when the logger program and wiring loom were being tested and debugged before transportation to site and to check the correct operation of the gauges before embedment in the concrete. Once the system had been verified as working correctly the cluster boxes were filled with silicone sealant fully to waterproof the connections and closed. 


\subsection{On-site work}

On arrival on site the datalogger, battery, interface box and ambient probes were first attached to their column before burying the gauge clusters and their multi-core connecting leads in the top of the sub-base. The strain gauges were transported to site in their packaging to reduce the risk of damage; however, once on site they were connected to pre-cut sections of reinforcement chair and tested for correct operation with the manual gauge readout box before being stored safely. After placement of the slip membrane the locations of the gauges were marked and the cable to connect the gauges to the cluster boxes was cut. These leads were connected, cable-tied to provide strain relief and waterproofed as early as possible, but the strain gauges were not attached until just before they were required, to avoid the risk of accidental damage.

Although precautions had been taken to provide strain relief to all of the connections, it was still felt necessary to reduce the possible movement in the cable runs. This was done by cabletying the leads to the bottom of the fabric reinforcement once it was placed or, in the case of fibre-reinforced slabs, taping them to the slip membrane.

Once the gauges had been fixed in place and connected to the datalogger, they were checked for correct operation as at this stage faulty gauges could still be replaced. When the time came to embed the gauges in the concrete they were first surrounded with concrete by hand, before concrete was allowed to flow gently around the gauges. At all times care was taken to ensure that no concrete fell directly on top of the gauges, as this sudden pressure could have been sufficient to damage them. After embedment, the location of the gauges was clearly marked, either by placing a road cone on top of the concrete (Fig. 11) or by having a technician stand over the gauge. This was done until the slab was finished by the LaserScreed ${ }^{\mathrm{TM}}$ machine when the risk of accidental damage ended.

\subsection{Post-construction work}

In some cases precision level surveys were carried out on the slabs after they had been cast and at subsequent intervals to assess the vertical movement of the slab's surface. The results obtained are only to a precision of $0.1 \mathrm{~mm}$, but this gives a good indication of the variations in the slab surface. The surveys were carried out on $1 \times 1 \mathrm{~m}$ or $2 \times 2 \mathrm{~m}$ grids to suit the floor area. Detail surveys were also carried out on all of the

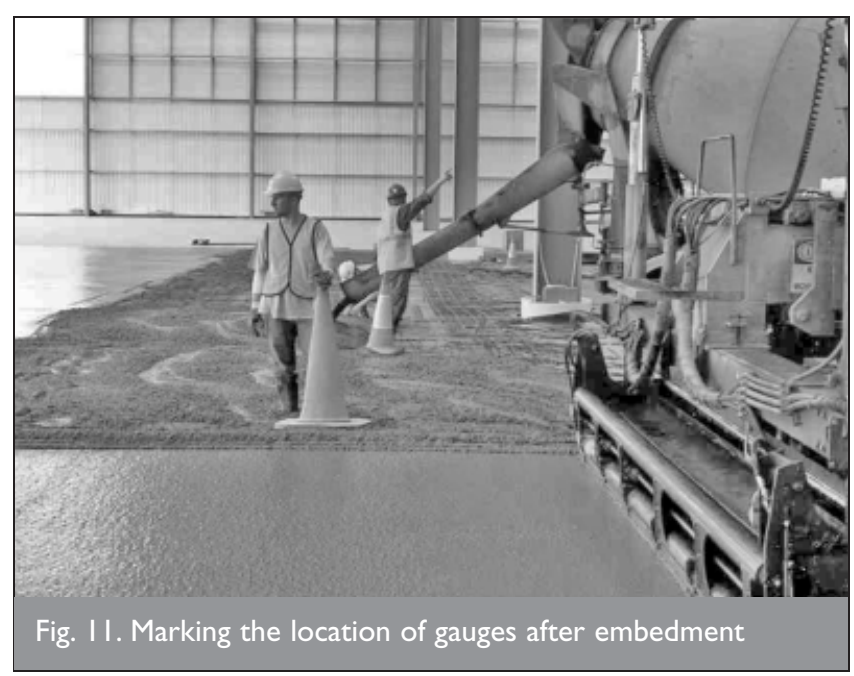

floors on subsequent data collection visits to locate and quantify any cracking in the floor.

\section{SAMPLE RESULTS}

As emphasised previously, the aim of this paper is to describe the successful development and implementation of in situ monitoring techniques for gathering information on the earlyage behaviour of concrete. Further papers ${ }^{3,4}$ will go on to present and discuss in detail the data collected from the site instrumentations. Some sample results are, however, included here to demonstrate the success of the instrumentation procedure that has been developed.

Figure 12 shows temperatures in the slab, sub-base and subgrade of one of the mesh-reinforced jointed large area pours. This floor formed part of a food distribution centre, and consisted of a $225 \mathrm{~mm}$ thick slab cast on a 1200 gauge polythene slip membrane laid on top of $150 \mathrm{~mm}$ of wellcompacted type 1 granular hardcore. Thermocouples were installed to measure temperature variations up to $0.8 \mathrm{~m}$ below the surface of the slab. After casting the concrete, the heat loss into the ground and air exceeds the rate of heat generation owing to cement hydration and this causes the temperature in the slab to drop initially (Fig. 12). Following this, the measured internal temperatures show a rapid rise, although thermal gradients remain fairly constant. When the rate of losses into the environment once again exceeds the rate of heat production, the temperature in the slab begins to drop from its peak. The influence of ambient temperatures can be seen (Fig.12) approximately $48 \mathrm{~h}$ after casting, and from this point onwards diurnal temperature changes are clearly visible on top of the continuing reduction in temperature towards ambient conditions.

As part of the research, a finite element model was developed to model the early-age thermal behaviour of the slabs. The modelling work is reported in greater detail elsewhere. ${ }^{5}$ Fig. 13 is included to show the agreement obtained between the model and the site-measured slab temperatures. The temperatures recorded by the thermistors embedded within the coil housing of two of the strain gauges are compared in Fig. 13 with temperatures predicted by the finite element at positions (nodes) corresponding to the strain gauges.

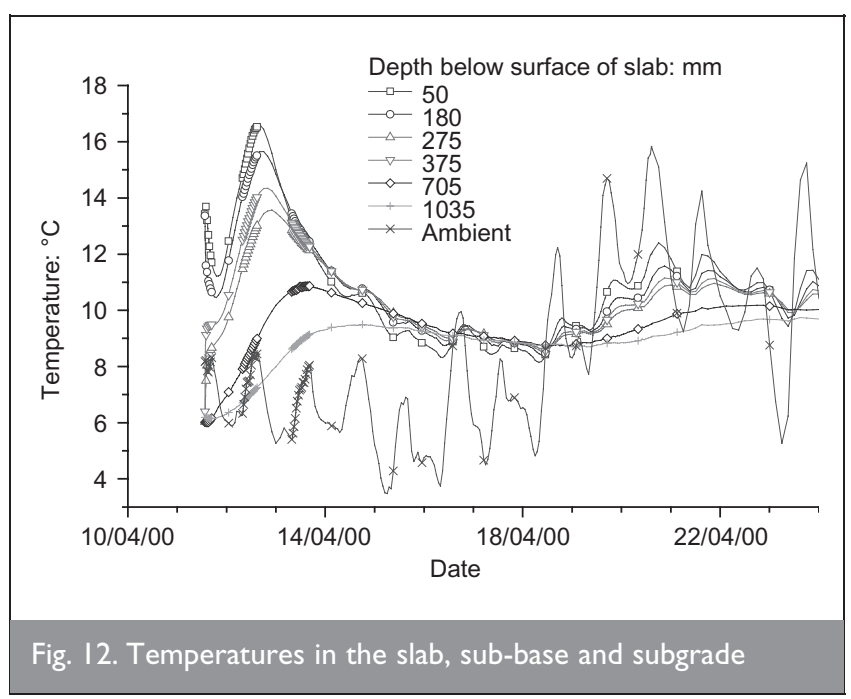




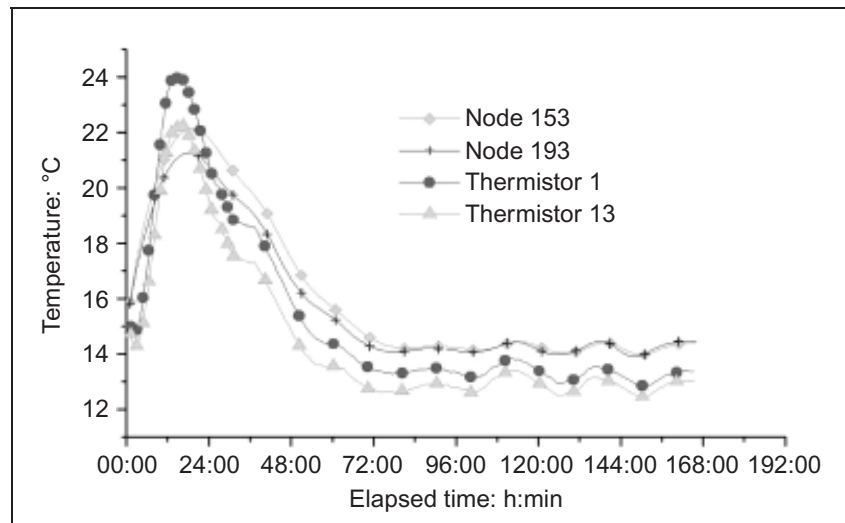

Fig. 13. Comparison of finite element predicted and measured temperatures in a slab

The movements recorded by the strain gauges positioned across a contraction joint in the mesh-reinforced long strip floor are shown in Fig. 14. Data from four gauges are given. In the gauge 1d (Fig. 14), 1 and 2 refer to two different positions along the joint. At each position there were two gauges (B and $\mathrm{T}$ ), which were $60 \mathrm{~mm}$ and $120 \mathrm{~mm}$ respectively from the bottom of the $260 \mathrm{~mm}$ thick slab.

The joint was saw-cut $24 \mathrm{~h}$ after the slab was constructed (point A in Fig. 14), although no significant movement occurred for a further $12 \mathrm{~h}$. A temperature drop $37 \mathrm{~h}$ after casting (point B Fig. 14) appears to have triggered the opening of the contraction joint, and then all gauges showed gradual joint opening with time over the next 20 days. The opening of the contraction joint was accompanied by contractions measured by other strain gauges embedded elsewhere in the slab. The magnitude of these movements (Fig. 15) decreased with distance from the joint, until at about $7 \mathrm{~m}$ from the contraction joint the movement was negligible. This suggests that not all parts of the slab had their built-up stresses relieved by the joint movement.

The measured movements from the strain gauges along with the concrete drying shrinkage for the long-strip slab are compared in Fig. 16 to theoretical predictions of long-term drying shrinkage obtained using Bazant and Baweja's ${ }^{12}$ B3 model. This model uses mix constituents and ambient conditions to predict the drying shrinkage of concrete.

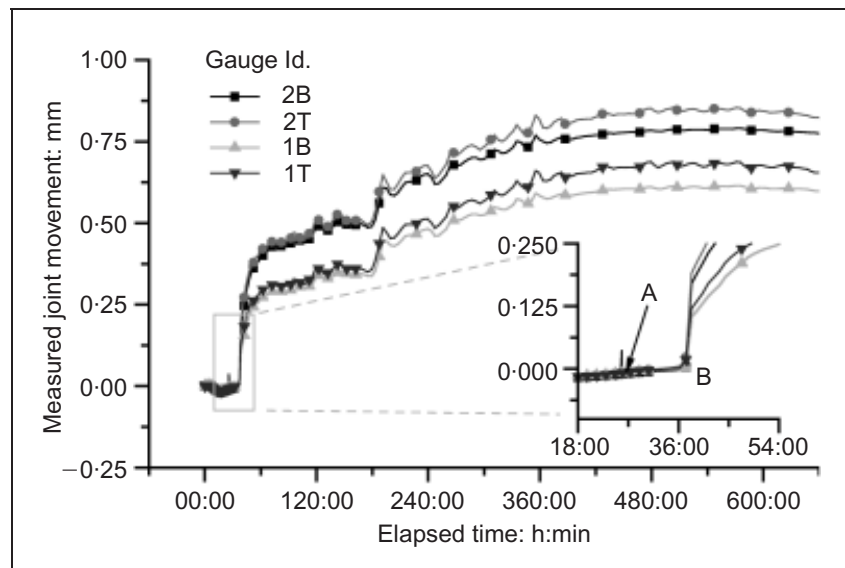

Fig. 14. Movements at a contraction joint

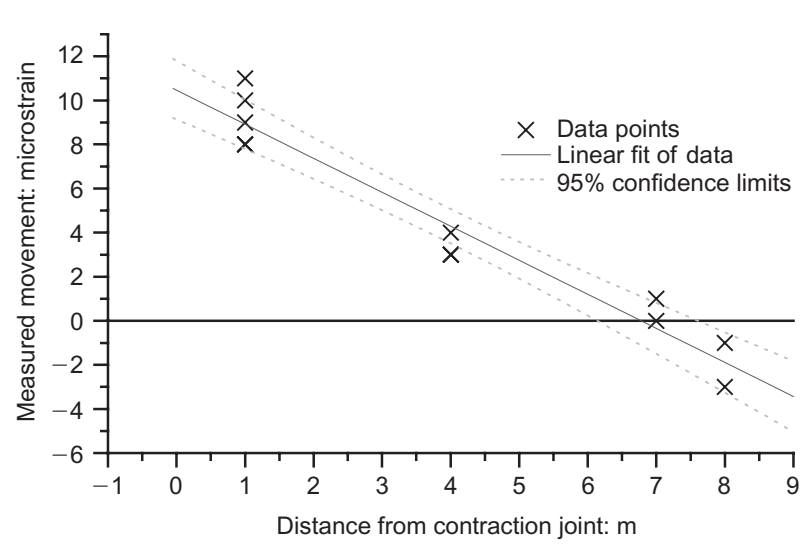

Fig. I5. Measured strain changes as a construction joint opened up $37 \mathrm{~h}$ after casting

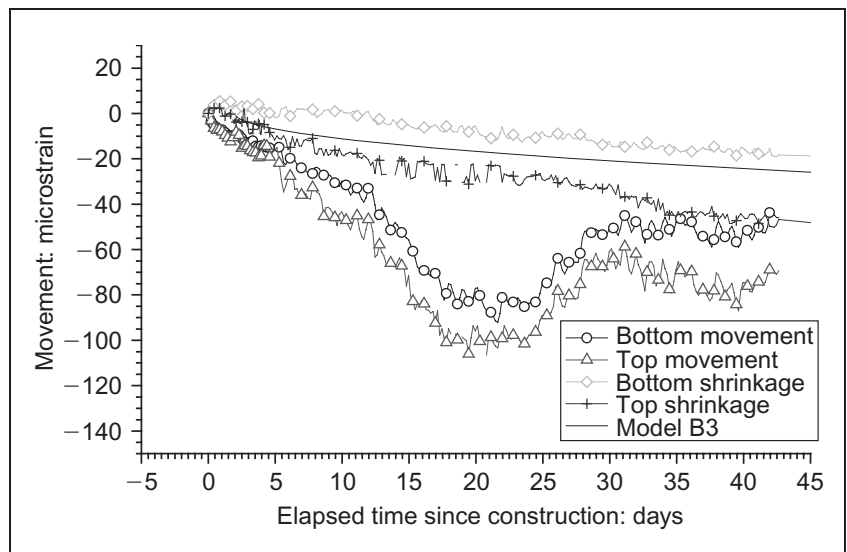

Fig. 16. Measured and theoretical slab shrinkage movements

Reasonable agreement is shown. Because of the polythene slip membrane, moisture can only be lost from the top surface of the slab and so the upper region of the slab undergoes greater shrinkage.

\section{CONCLUSIONS AND RECOMMENDATIONS}

A site instrumentation methodology has been developed through the instrumentation and early-age monitoring of floor slabs in six buildings, but which could be applied to any concrete structure. This will permit the monitoring of concrete strains and movements from very early ages after concrete casting right through to movements caused by the loads on the structure in service, if desired. The following checklist summarises the main activities to be carried out for a structural instrumentation.

(a) Obtain drawings of the structure and locate key locations for instrumentation.

(b) Select and obtain suitable sensors, datalogger and cabling equipment.

(c) Design wiring loom and write logger program.

(d) Wire-up interface box and gauge clusters.

(e) Test wiring set-up and logger program.

(f) Transport to site.

(g) Fix logger and ambient instrumentation in place.

(h) Install and protect cables from interface box to gauge clusters. 
(i) Mark the gauge locations and fix the leads from the cluster boxes in place.

(j) Fix the gauges rigidly in place and connect leads: the gauges should be connected in place as they are needed; the crimp connections should be cable tied to provide strain relief and waterproofed with tape; the correct functioning of the gauge should be verified.

(k) Embed the gauge in concrete: concrete should be placed all around the gauge with care being taken to prevent concrete from dropping directly onto the gauge.

(l) Monitor performance: the datalogger is left on site recording readings; periodic access is required to download data.

The recommended methodology provides a robust and reliable method for locating the strain gauges which should not disrupt the construction process. Mounting the gauges on reinforcement chairs enables them to be placed quickly, accurately and securely. The newly developed gauges have worked well, although special care is required when installing the $254 \mathrm{~mm}$ steel strain gauges as their additional length makes them more vulnerable to damage. The gauges for monitoring across day joints are an important development and open up many new possibilities for engineers who want to monitor across construction joints in all kinds of structures.

The limited results presented in this paper confirm the success of the methodology of data capture and give an insight into the early-age temperature development and movements in concrete industrial ground-floor slabs.

\section{ACKNOWLEDGEMENTS}

The authors acknowledge the financial support of the EPSRC and thank the members of the project steering group, the Association of Concrete Industrial Flooring Contractors and their industrial partners BRC Ltd, Burks Green, The Concrete Society, Face Consultants Ltd, Fibercon UK Ltd, Fibermesh Europe, Stanford Industrial Concrete Flooring Ltd, Stuarts Industrial Flooring Ltd, The Sprigg Little Partnership, Tarmac Topmix Ltd. and the Quarry Products Association. The research team is also grateful to Booker, ANC, Wincanton Logistics and Asda for granting access to their sites to embed instrumentation, to Gage Technique International for their invaluable support and advice, and to the British Atmospheric Data Centre for granting access to the surface weather station data.

\section{REFERENCES}

1. Austin S. A., Robins P. J. and Bishop J. W. Behaviour and design of concrete industrial ground floors. Concrete, 1998, 32, No. 6, 8.

2. Sмiтн R. A. Practical advice for practising engineers. The Structural Engineer, 1998, 76, No. 7, 143.

3. Вishop J. W. Early Age Behaviour of Concrete Industrial Ground Floor Slabs. PhD thesis, Loughborough University, 2001.

4. Austin S. A., RoBinS P. J. and BISHOP J. W. Behaviour and Design of Concrete Industrial Floor Slabs. Department of Civil \& Building Engineering. Loughborough University, 2000, final report for EPSRC.

5. Robins P. J., Bishop J. W. and Austin S. A. Early-age finite element modelling of concrete industrial floors.

Proceedings of the Institution of Mechanical Engineers. Part L: Journal of Materials: Design and Applications, 217, 295-307.

6. Project website. See: http://www.lboro.ac.uk/departments/ $\mathrm{cv} /$ research/projects/concretefloorbehaviour.

7. BARNBROOK G. and BECKETT D. Technical Report 34: Concrete Industrial Ground Floors: A Guide to their Design and Construction. 2nd end. The Concrete Society, Slough. 1994.

8. Technical Report 34: Concrete Industrial Ground Floors: A Guide to their Design and Construction. $3^{\text {rd }}$ edn. The Concrete Society, Crowthorne, 2003.

9. Boulay C. and PATIES C. Mesure des déformations du béton au jeune âge. Materials and Structures, 1993, 26, 307-311.

10. Neville A. M. Properties of Concrete. 4th edn, Harlow, Longman Group Limited, 1995.

11. See: http://www.campbellsci.com/centers/structurezcement.html

12. BAZANT Z. P. and BAWEJA S. Creep and shrinkage prediction model for analysis and design of concrete structures: model B3. Materials and Structures, 1995, 28, No. 180, 357.

\section{What do you think?}

To comment on this paper, please email up to 500 words to the editor at journals@ice.org.uk

Proceedings journals rely entirely on contributions sent in by civil engineers and related professionals, academics and students. Papers should be 2000-5000 words long, with adequate illustrations and references. Please visit www.thomastelford.com/journals for author guidelines and further details. 